\title{
To Assess and Compare Dental Consultancy Charges of Different Geographical Areas of the Metropolitan City Karachi
}

\author{
Maryam $^{1}$, Qaiser Ali Baig², Esha Abrar ${ }^{1}$, Ashar Afaq ${ }^{3}$, Wajiha Anzar ${ }^{4}$ and Salman Shams ${ }^{5 *}$ \\ ${ }^{1}$ Lecturer, Community Dentistry Department, Faculty of Dentistry, Dow International Dental College, Dow University of \\ Health Sciences, Pakistan \\ ${ }^{2}$ Associate Professor, Community Dentistry Department, Faculty of Dentistry, Dow International Dental College, Dow \\ University of Health Sciences, Pakistan \\ ${ }^{3}$ Associate Professor, Community Dentistry Department, Faculty of Dentistry, Dow International Dental College, Dow \\ University of Health Sciences, Pakistan \\ ${ }^{4}$ Lecturer, Community Dentistry Department, Faculty of Dentistry, Dow International Dental College, Dow University of \\ Health Sciences, Pakistan \\ ${ }^{5}$ Senior Lecturer, Oral and Maxillofacial Surgery Department, Faculty of Dentistry, Liaquat University of Medical and Health \\ Sciences, Pakistan
}

\begin{abstract}
Objectives: To identify consultation and also procedure charges in accordance with experience and qualifications and to assess variations in these consultation charges according to different geographical town of Karachi.To assess charges in public private sectors also according to different geographical towns of Karachi.
\end{abstract}

Study Design: cross-sectional survey.

Setting: Towns of Karachi city

Study Duration: 4 months

Methodology: The data was collected by means of questionnaire, 200 hospitals clinics and polyclinics were assessed.

Results: It showed there were more male practitioners than females. The consultation charges range from free consultation to few thousand rupees. Similarly, the procedural charges also range in between public private and within them as well. The public sectors are charging lesser in compare with private sectors, the most economical towns were Safoora Goth, Mahmoodabad and Sadder whereas Defense and Bahadurabad were the most expensive townswhere $p$ value found significant $(0.015)$.

Conclusion: Variations in the prices for healthcare having larger impact on overall health. Policymakers should focus on measures within an integrated approach.

KEYWORDS: Dental; Charges; Private \& Government clinics

Quick Response Code:

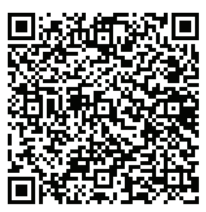

Address for correspondence: Salman Shams, Senior Lecturer, Oral and Maxillofacial Surgery Department, Faculty of Dentistry, Liaquat University of Medical and Health Sciences, Pakistan

Received: January 23, $2021 \quad$ Published: February 08, 2021

How to cite this article: Maryam, Qaiser Ali B, Esha A, Ashar A, Wajiha A, Salman S. To Assess and Compare Dental Consultancy Charges of Different Geographical Areas of the Metropolitan City Karachi. 2021- 3(1) OAJBS.ID.000254. DOI: 10.38125/OAJBS.000254 


\section{INTRODUCTION}

A great burden of dental problem is considered as one of the major health issues of all developing countries [1]. These problems were not only affected oral health but also compromise the quality of life [2].

Whereas at the same time increasing healthcare cost is one of the leading major issues in healthcare systems around the world. Moreover, global financial crisis has reduced the availability of health system resources [3].

When it comes to consulting a dentist, several different factors are considered before a patient chooses any dental service provider. These include professional experience of the dentist, environment of clinic, OPD and availability of different treatments being provided among others [4].

Consideration of factors that patient values, form a vital element of assuring quality service to the patient. Factors like expensive treatment may prove to be a barrier to health service utilization by general public. These factors vary from individual to individual and between different communities [5].

However, there is little available information on the cost of dental services on availability of materials and equipment's $[6,7]$. The majority of dentist's charge fee based on treatment they provide. Some have their own standard of charging fee according to their experience, qualification and locality. Some dentists give treatment on fee-free basis while others charge according to patient compliance and affordability.

Currently there is no framework is existing for consultation charges in Karachi. Service providers are charging by their own wish. Survey is must needed which provides a basic information on the fee structure followed by dentist for different procedures, so that policy makers can be able to generate a policy that is feasible, affordable to the masses with quality services that are acceptable and sustainable for a fair period of time.

\section{METHODOLOGY}

Cross-sectional study was done for a period of four months in different towns of Karachi city. Total 200 hospitals clinics and polyclinics both government and private sectors was assessed. Clinics and hospitals that were included in this survey was identified by the help of Google map and online marketing webpages.

Data were obtained by means of self-administere dquestionnaire, principal investigator reached to different hospital and clinic setups of both private and public sector, informed consent was obtained from of the respondents before the questionnaires were given to all of the selected dentists, also purpose of the research briefly explained to them along with making them sure their responses will be treated with utmost concern and confidentiality. Questionnaire was consisting of two sections.

Section A consists of details of practitioner and their health care setting details.

Section B consists of consultation and procedural charges they offered in clinics and hospitals.

The Questionnaires that presented to the professionals included consultation charges, Amalgam and composite filling charges, scaling charges, Teeth extraction charges and root canal treatment charges with other basic information.
The data collected was recorded and analyzed using a statistical package for social sciences (SPPS 20.0). The frequency distribution is calculated, and data were analyzed for any association or correlation between sociodemographic and other variables using statistically applied test like chi square and linear regression. A $P$-value of $<0.05$ will be considered as significant.

\section{RESULTS}

Table 1: Age of the practitioner.

\begin{tabular}{|c|c|}
\hline \multicolumn{2}{|c|}{ Age Description } \\
\hline Range & 43 \\
\hline Minimum & 22 \\
\hline Maximum & 65 \\
\hline Mean & 35.825 \\
\hline Std: Deviation & 9.46745 \\
\hline
\end{tabular}

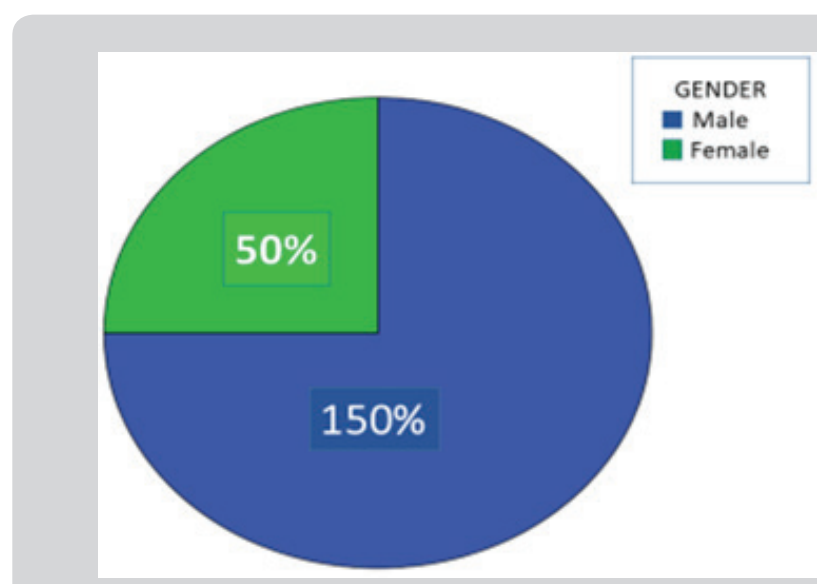

Figure 1: Gender distribution.

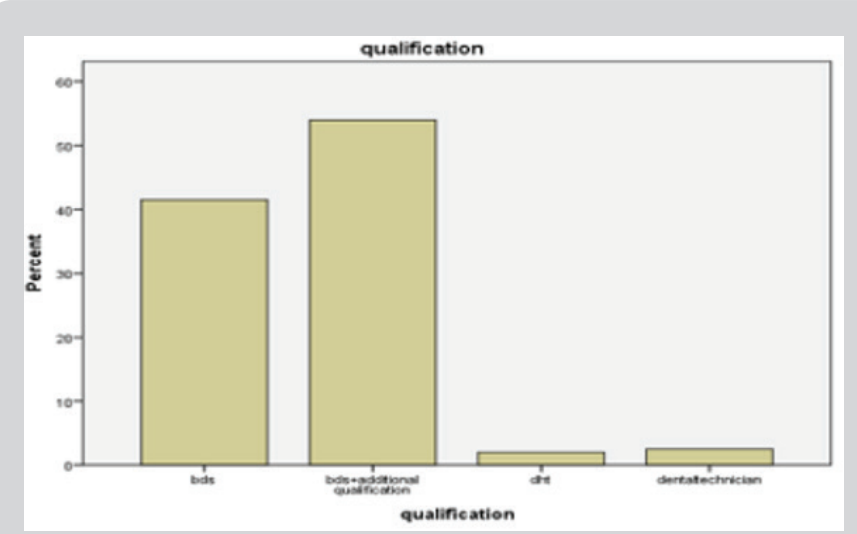

Figure 2: Qualification of dental practitioner.

Dentists working in different towns of Karachi city were assed to know about the charges begin charged by them. The results show that mean age of health care provider ranged between $35.8+-9.46$ years as shown in Table 1. The pie graph in Figure 1 showed there were more male practitioners were working in city. Nearly $93.5 \%$ of dentists worked in private sector $\& 6.5 \%$ were from public sector as shown in Figure 2. Majority of dentists 55.5\% had BDS degree, 42\% had BDS with additional qualification \& remaining $2.5 \%$ possess DHT only as shown in the Figure $3 \& 4$, consultation charges range from free consultation to few thousand rupees, as shown in tables Similarly, the procedural charges also range in between public 
private and within them as well, as shown in Table $2 \& 3$, where $p$ value found significant $(0.015)$ shown in Table $4 \& 5$.

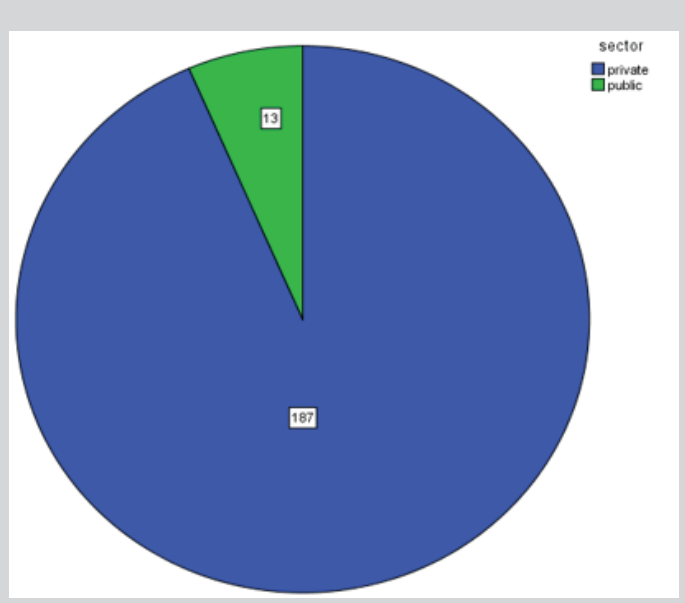

Figure 3: Sectors distribution.

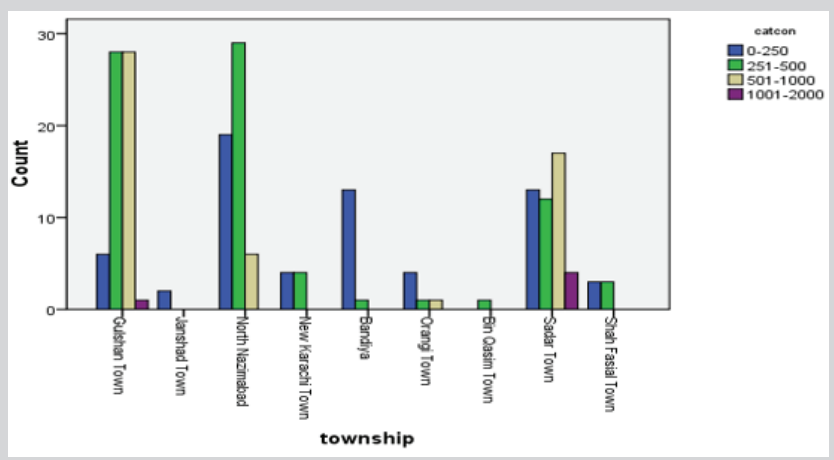

Figure 4
Table 2: Number of the hospitals and clinics.

\begin{tabular}{|c|c|c|}
\hline \multicolumn{3}{|c|}{ Dental Setting } \\
\hline & Frequency & Percent \\
\hline Hospital & 31 & 15.5 \\
\hline Clinic & 168 & 84 \\
\hline Poly clinic & 1 & 0.5 \\
\hline Total & 200 & 100 \\
\hline
\end{tabular}

Table 3: Names of towns.

\begin{tabular}{|c|c|c|}
\hline Names of Towns & Frequency & Percent \\
\hline Gulshan-e- Iqbal & 36 & 18 \\
\hline North Nazimabad & 23 & 11.5 \\
\hline Gulistan-e-Jauhar & 10 & 5 \\
\hline North Karachi & 8 & 4 \\
\hline Safoora Goth & 1 & 0.5 \\
\hline Defence & 17 & 8.5 \\
\hline Baldia & 14 & 7 \\
\hline Orangi Town & 6 & 3 \\
\hline Malir & 6 & 3 \\
\hline Saddar & 22 & 11 \\
\hline Nazimabad & 8 & 4 \\
\hline Chanesar Goth & 2 & 1 \\
\hline Buffer Zone & 7 & 3.5 \\
\hline Clifton & 7 & 8 \\
\hline Bahadurabad & 16 & 0.5 \\
\hline FB Area & 16 & 100 \\
\hline Gulshan-e- Maymar & 1 & \\
\hline Total & 200 & 8 \\
\hline
\end{tabular}

Table 4: Consultation charges.

\begin{tabular}{|c|c|c|c|c|c|c|c|c|c|c|c|c|c|c|c|c|c|c|c|}
\hline & Free & 20 & 50 & 80 & 100 & 120 & 200 & 300 & 350 & 400 & 500 & 600 & 700 & 750 & 800 & 1000 & 1500 & 2000 & total \\
\hline & Private & 14 & 1 & 5 & 1 & 16 & 1 & 17 & 21 & 1 & 6 & 50 & 2 & 6 & 3 & 37 & 4 & 1 & 187 \\
\hline & Public & 6 & 1 & 0 & 0 & 1 & 0 & 1 & 0 & 0 & 0 & 1 & 0 & 0 & 1 & 2 & 0 & 0 & 13 \\
\hline Total & & 20 & 2 & 5 & 1 & 17 & 1 & 18 & 21 & 1 & 6 & 51 & 2 & 6 & 4 & 39 & 4 & 1 & 200 \\
\hline
\end{tabular}

Table 5: $P$ - value.

\begin{tabular}{|c|}
\hline $\boldsymbol{P}$ - value \\
\hline 0.015 \\
\hline
\end{tabular}

\section{DISCUSSION}

This survey was conducted in 9 different towns of Karachi, to know about charges being charged by different sectors, in accordance with their, qualifications and working experience at the most general level, no distinctive relation seen between the costs being charged by service provider, and along with the height of people spending money on healthcare. Therefore, it can be said that healthcare facilities have their prices set independently, variations also persisted within regional and district facilities. Where the areas of Defense and Bahadurabad showed have high consultation fees while remaining towns including Safoora town have showed low consultation fees. This result coincides with study done in Tanzania et al. [8] where they also observed regional differences in fee structure.
However, by considering at specific services, we founded very limited links in between the actual coverage for any specific services and cost-sharing arrangements for these specific services. It was observed that quality of materials is an important factor for high charges as compared with the intermittent availability and quality of dental materials. Whereas low-income dental setups used substandard material and average technology while premium quality materials and Avant grade contemporary technology leads to the extravagant. It is also possible that the equipment availability influences the availability of materials. Another study done in past also showed dental care provided to people varying socioeconomic availability [9].

At a higher level, difficulty increases for policy makers to increase costs for treatment as many people cannot afford high rates. However, this creates substandard treatment most of the time as the cost being charged doesn't cover for the cost of proper and premium level instruments [10]. 
The findings of this results were comparable by another records comes from the USA which also showed very slight variations at the macro level between group of small employer health plans and in compare with the state or federal policies [11]. Another international survey was done to map up the health policy responses towards the financial crisis it showed that overall, the constitutional package for benefits was not totally changed, but that some reductions were carried out, it is always very difficult for any of the policymakers to completely exclude essential health care services, because many of the services were beneficial for certain subgroups of populations [12].

Another study was conducted which determine the factors affecting the patients' choice for dental services in Pakistan in 2013 showed the results that the majority of the patients; irrespective of their earnings considered environment as highly preferable things when choosing a dental facility [6].

Factors which affect charges might include professional experiences, friendly and attention paying dental consultations and availability of different dental treatments vastly affects the consultation charges as present in developed areas [13]. Developed areas like Gulshan town having to about 29 clinics had consultation charges ranging from PKR500-2000 and 6 dental clinics having PKR500-2000 in North Nazimabad while underdeveloped areas not having a vast availability of dental treatments such as Orangi town, having only 1 dental clinic ranging from PKR500-2000 and Baldia town having 0 dental clinics in PKR500-2000 range.

However, considering some of the International researches, European countries revealed that by increasing user charges will lead towards inequality between high and low incomes [14]. The European Observatory concluded that the cost-sharing policy should be done in systematic and evidence-based manner. In England, an organization called NICE had develop a list of 'do not do' recommendations which was derived from ethical clinical practice guidelines, that were aimed for excluding lower-value health services for certain subgroups population [14]. In the countries like United States and Canada, they established an campaign named as Choosing Wisely campaign for reduction of unnecessary tests, and also pointless treatments as well as procedures [15]. Unwarranted geographical practice variation in healthcare was set on the agenda by Wennberg as an important cost driver in healthcare. However, the implementation of equal healthcare facilities to every individual it requires more focus in making health policy [16].

\section{CONCLUSION}

It was concluded that variations in the prices for healthcare having larger impact on overall health. Policymakers should focus on measures within an integrated approach.

\section{LIMITATIONS}

a) The primary limitations of this analysis relate to data availability and quality. b) Common to other health professions, no data in dentistry are available on the relationship between different towns and fee structure.

c) Limited time duration.

\section{REFERENCES}

1. Pickett KE, Wilkinson RG (2015) Income inequality and health: a causal review. Soc Sci Med 128: 31626.

2. Hafeez K, Aiyesha W (2018) Feedback in Pakistan's medical \& dental education system. J Pak Dent Assoc 1(2): 3.

3. Mladovsky P, Srivastava D, Cylus J, Karanikolos M, Evetovits T, et al. (2012) Health policy responses to the financial crisis in Europe.

4. Shabbir A, Malik SA, Malik SA (2016) Measuring patients' healthcare service quality perceptions, satisfaction, and loyalty in public and private sector hospitals in Pakistan. Int J Qual Reliab Manag 33(5): 538-557.

5. Xesfingi S, Vozikis A (2016) Patient satisfaction with the healthcare system: Assessing the impact of socio-economic and healthcare provision factors. BMC Health Serv Res 16(1): 94.

6. Iqbal M, Jameel A, Girach MM (2014) Factors affecting patients' choice of dental services. PODJ 34(4)

7. Corlette S, Lucia KW, Levin M (2013) Implementing the affordable care act: choosing an essential health benefits benchmark plan. Issue brief J CWF 15: 1-14.

8. Nyamuryekung'e KK, Lahti SM, Tuominen RJ (2015) The relative patient costs and availability of dental services, materials and equipment in public oral care facilities in Tanzania. BMC Oral Health 15(1): 74.

9. Maharani DA, Rahardjo A (2012) Is the utilisation of dental care based on need or socioeconomic status? A study of dental care in Indonesia from 1999 to 2009. Int Dent J 62(2): 90-94.

10. Thomson S, Jowett M, Evetovits T, Jakab M, McKee M, et al. (2013) Health, health systems and economic crisis in Europe: impt Pol Impact.

11. Beronio K, Glied S, Frank R (2014) How the affordable care act and mental health parity and addiction equity act greatly expand coverage of behavioral health care. JBehav Health Ser R 41(4): 410-28.

12. Greß S, Niebuhr D, Rothgang H, Wasem J (2005) Criteria and procedures for determining benefit packages in health care: a comparative perspective. Health Pol 73(1): 78-91.

13. Batbaatar E, Dorjdagva J, Luvsannyam A, Savino MM, Amenta P (2017) Determinants of patient satisfaction: a systematic review. Perspect. Public Health 137(2): 89-101.

14.Van der Wees PJ, Wammes JJ, Westert GP, Jeurissen PP (2016) The relationship between the scope of essential health benefits and statutory financing: an international comparison across eight European countries. Int J Health Policy Mant 5(1): 13.

15. Levinson W, Kallewaard M, Bhatia RS, Wolfson D, Shortt S (2015) Choosing wisely: a growing international campaign. BMJ Qual Saf 24(2): 167-174.

16. Wennberg JE (2004) Practice variations and health care reform: Connecting the dots: A focus on medical error is preventing sufficient focus on improving the quality of patient decision making to reduce practice variations (and costs) in today's health care system. Health Aff. (Millwood). 23(Suppl2): VAR-140-VAR-4. 